\title{
РОЛЬ МЕЖДУНАРОДНЫХ КОРПОРАЦИЙ В ФОРМИРОВАНИИ ИННОВАЦИОННОЙ ЭКОНОМИКИ РОССИИ
}

\section{THE ROLE OF INTERNATIONAL CORPORATIONS IN THE INNOVATION ECONOMY OF RUSSIA}

\section{A. Fedchenko}

Summary. Today, international corporations are one of the leading actors in production, scientific and technical processes and influence the economies of host countries, including through the introduction of innovations and stimulation of the innovative nature of the economy. The article examines the theoretical provisions on the impact of innovation activities of TNCs on the Russian economy. Particular emphasis is placed on the factors that determine the leadership of international corporations in the production of innovations. Also, in the course of the research, a methodology was proposed for assessing the impact of corporations' activities on the formation of the innovative economy of the Russian Federation.

Keywords: international corporations, TNC, innovations, innovative economy, investments, economic effects.
B мировой экономике огромную роль играют международные корпорации. Сегодня они, по сути, формируют вектор развития глобальной экономической системы, непрерывно расширяя регионы своего присутствия и захватывая новые рынки сбыта.

Транснационализация мировой экономики началась с формирования информационного общества и перехода к постиндустриальному типу экономического хозяйствования. В течение нескольких последних десятилетий наблюдается процесс глобализации и интеграции, как политико- экономической, так и культурной. Соответствующие изменения характерным образом оставляют свой след преимущественно в сфере экономики. Основой этих изменений является государственное и научно- техническое воздействие в вопросах формирования и развития международного взаимодействия и сотрудничества [3].

По данным исследований ВШЭ, на деятельность международных корпораций приходится около $25 \%$ мирового ВВП. Они также обслуживают около 70\% всей мировой торговли, владеют $80 \%$ патентов лицензий и ноу-хау, являются активными инвесторами в НИОКР (80\%), а также осуществляют почти 90\% прямых иностранных инвестиций [2].
Федченко Анастасия Марковна

Аспирант, Кубанский государственный университет nestezzy@mail.ru

Аннотация. Сегодня международные корпорации являются одним из ведущих субъектов производственных, научно-технических процессов и воздействуют на экономики принимающих стран, в том числе - за счет внедрения инноваций и стимулирование инновационного характера экономики. В статье рассмотрены теоретические положения о влиянии инновационной деятельности ТНК на экономику России. Особый акцент сделан на факторах, которые обуславливают лидерство международных корпораций в производстве инноваций. Также в процессе исследования предложена методика оценки воздействия деятельности корпораций на формирование инновационной экономики РФ.

Ключевые слова: международные корпорации, ТНК, инновации, инновационная экономика, инвестиции, экономические эффекты.

Во второй половине XX века крупные глобальны корпорации стали реализовывать стратегию трансфера высокотехнологичных производств и научно-исследовательских разработок в развивающиеся страны. В результате этого локальные представительства транснациональных корпораций (ТНК) получили уникальную возможность осуществления инновационной деятельности. И если в середине XX века объем инвестиций глобальных корпораций в зарубежные научные исследования составлял всего лишь 4\%, то в 70-е годы XX века эта цифра достигла 10\%, а еще через 10 лет - 15\% [4].

На сегодняшний день международные корпорации являются важнейшим элементом международной структуры НИОКР, благодаря наличию доступа к значительным финансовым, материально-техническим и человеческим ресурсам. Они способны привлекать лучшие научные и исследовательские кадры и организовывать НИОКР в глобальных масштабах.

Ядро мировой экономики представляют около 100 крупнейших ТНК, важность роли которых можно оценить по следующим данным: ТНК контролируют примерно 2/3 мировой торговли, и 40\% этой торговли осуществляется внутри ТНК по трансфертным ценам; на THК 
Таблица 1. Крупнейшие иностранные компании, ведущие деятельность на территории России на 2017 год [3]

\begin{tabular}{|l|l|l|l|}
$\begin{array}{l}\text { Номер в рей- } \\
\text { тинге }\end{array}$ & Название & Выручка, млрд. руб. & $\begin{array}{l}\text { Численность персонала } \\
\text { в России }\end{array}$ \\
\hline 1 & Groupe Auchan & 414 & 38960 \\
\hline 2 & Metro Group & 305 & 22353 \\
\hline 3 & Japan Tobacco International & 245 & 4500 \\
\hline 4 & Philip Morris International & 244 & 4100 \\
\hline 5 & Toyota Motor & 230 & 2600 \\
\hline 6 & IKEA & 200 & 12400 \\
\hline 7 & PepsiCo & 172 & 20000 \\
\hline 8 & Volkswagen Group & 171 & 4500 \\
\hline 9 & Daimler (Mepседес-Бенц) & 157 & 1400 \\
\hline 10 & Leroy Merlin & 152 & 19000 \\
\hline
\end{tabular}

приходится около 50\% мировой промышленности; ТНК контролируют примерно 4/5 существующих в мире патентов, лицензий и ноу-хау.

ТНК осуществляют инвестиции, приносят новые технологии производства и управления, увеличивают ВВП, положительно влияют на платежный баланс, увеличивая экспортную выручку или снижая импорт - эти изменения укрепляют экономику страны, повышают уровень жизни ее граждан.

Вклад ТНК в мировую экономику носит неоднозначный характер: с одной стороны, они являются следствием интернациональных отношений в сфере экономики, с другой - выступают определенным регулятором, рычагом воздействия на них, с возможностью серьезного видоизменения международного сотрудничества, приносящего не всегда положительный вклад в их развитие.

В России деятельность международных корпораций, с одной стороны, выступает драйвером различных инновационных процессов, а, с другой стороны, является источником разнообразных противоречий социального и эконмического характера, обусловленных спецификой российской действительности.

Ежегодно в нашей стране фиксируется рост иностранных компаний - акционерных обществ, представительств, дочерних предприятий, основные акции которых принадлежат иностранным собственникам.

Данные таблицы 1 свидетельствуют о наличии ТНК на российском рынке, и их влиянии на российскую экономику.

Параллельно с увеличением количества ТНК на территории России, происходит рост инвестиций в российскую экономику.
Международные компании является одной из важных составляющих мировой иерархии НИОКР. Они обладают достаточными ресурсами, претерпевают незначительные рисков от финансовых потерь при проведении инновационной деятельности. Поскольку последняя не является основной сферой хозяйствования международных компаний, то в случае успешного восприятия новинки на рынке они получают сверхприбыль $[1,6]$.

О значении ТНК в мировом создании нововведений свидетельствует тот факт, что им принадлежит более $2 / 3$ частных средств и половина мировых расходов на проведение научно-технологических разработок.

Анализ деятельности транснациональных корпораций позволяет определить ряд факторов, обуславливающих лидерство международных корпораций среди других субъектов мировой экономики в производстве инноваций. Прежде всего, именно ТНК часто становятся исполнителями госзаказа на производство инновационной продукции, в основном в отраслях оборонно-промышленного комплекса [5].

В кризисные периоды, когда стоимость компаний существенно снижается, мелкие и средние предприятия становятся мишенью для крупных международных корпораций.

Обобщая макроэкономические эффекты инновационной деятельности ТНК в России, следует еще раз уточнить, что они могут носить как позитивный, так и негативный характер (таблица 2).

Вопрос воздействия международных корпораций на инновационное развитие российской экономики в виду своей высокой актуальности находит широкое отражение в отечественной научной литературе. В ра- 
Таблица 2. Макроэкономические эффекты воздействия международных корпораций на инновационное развитие экономики РФ

\begin{tabular}{|c|c|c|}
\hline Сфера влияния & Позитивные эффекты & Негативные эффекты \\
\hline $\begin{array}{l}\text { Уровень развития российского } \\
\text { производства }\end{array}$ & $\begin{array}{l}\text { Российские предприятия получают доступ } \\
\text { к инновационным технологиям и ноу- } \\
\text { хау глобальных корпораций, что ведет } \\
\text { к оптимизации издержек и повышает } \\
\text { производительность труда в отрасли }\end{array}$ & $\begin{array}{l}\text { Интеграция отечественных предприятий } \\
\text { с международными корпорациями } \\
\text { способствует монополизации рынка }\end{array}$ \\
\hline Уровень менеджмента & $\begin{array}{l}\text { Внедрение прогрессивных методов } \\
\text { управления, обучение персонала } \\
\text { в соответствии с международными } \\
\text { стандартами }\end{array}$ & $\begin{array}{l}\text { Оптимизация персонала и, как следствие, } \\
\text { сокращение работников }\end{array}$ \\
\hline $\begin{array}{l}\text { Модернизация производственных } \\
\text { мощностей }\end{array}$ & $\begin{array}{l}\text { Распространение технологий } \\
\text { производства и моделей управления } \\
\text { глобальных корпораций. }\end{array}$ & $\begin{array}{l}\text { Происходит развитие преимущественно } \\
\text { капиталоемких, а не трудоемких отраслей }\end{array}$ \\
\hline Система дистрибуции товаров и услуг & $\begin{array}{l}\text { В результате интеграции } \\
\text { с транснациональными компаниями } \\
\text { российские предприятия получают } \\
\text { доступы на внешние рынки }\end{array}$ & $\begin{array}{l}\text { Сокращение связей с местными } \\
\text { поставщиками в результате интеграции } \\
\text { с глобальными корпорациями }\end{array}$ \\
\hline
\end{tabular}

\section{Источник: составлено автором}

Таблица 3. Комплексный подход к оценке степени воздействия ТНК на инновационный характер российской экономики

\begin{tabular}{|c|c|}
\hline Критерий & Система показателей \\
\hline 1. Общие показатели & $\begin{array}{l}\text { динамика и структура притока прямых иностранных инвестиций; } \\
\text { динамика увеличения рабочих мест, созданных иностранными корпорациями; } \\
\text { динамика импорта инновационных технологий, внедряемых представительствами ТНК } \\
\text { на территории РФ; } \\
\text { динамика оборота иностранных ТНК в ВВП принимающей страны }\end{array}$ \\
\hline \multirow[b]{2}{*}{ 2. Макроэкономические показатели } & $\begin{array}{l}2.1 \text { Доля накопленных прямых иностранных инвестиций в ВВП РФ } \\
\text { FDI }^{\text {GDP }}=\frac{\text { FDI inward stock }}{\text { GDP }} * 100 \% \text {, } \\
\text { где FDI }^{\text {GDP }}-\text { доля накопленных ПИИ в ВВП принимающей страны; } \\
\text { FDI inward stock - стоимостной объем накопленных ПИИ; } \\
\text { GDP - валовой внутренний продукт. }\end{array}$ \\
\hline & $\begin{array}{l}\text { 2.2 Доля выпуска инновационной продукции представительствами международных } \\
\text { корпораций } \\
\mathrm{FAO}^{\mathrm{GDP}}=\frac{\text { Output }^{\mathrm{FA}}}{\mathrm{GDP}} * 100 \% \\
\text { где FAO }{ }^{\mathrm{GDP}-} \text { доля выпуска инновационной продукции иностранными корпорациями в ВВП } \\
\text { PФ; } \\
\text { Output }^{\mathrm{FA}} \text { - выпуск продукции международных корпораций. }\end{array}$ \\
\hline 3. Производительность труда & $\begin{array}{l}\text { Prod }^{\mathrm{FA}}=\frac{\text { Output }^{\mathrm{FA}}}{\text { Staff }^{\mathrm{FA}}} \\
\text { где Prod }^{\mathrm{FA}} \text { - производительность труда на предприятиях международных корпораций в РФ; } \\
\text { Output }^{\mathrm{FA}} \text { - выпуск (оборот) продукции международных компаний в России; } \\
\text { Staff }^{\mathrm{FA}} \text { - доля занятых в филиалах иностранных компаний в России. }\end{array}$ \\
\hline
\end{tabular}

\section{Источник: $[2,5,7]$}

ботах $[8,9]$ представлены многочисленные научные подходы и модели оценки влияния деятельность ТНК на развитие инноваций в стране. Обобщая различные методики, целесообразно предложить комплексную модель оценки воздействия международных корпораций
В формировании российской экономики инновационного типа (таблица 3).

Сегодня глобализация мировой экономики определяется как неоднозначный, несоразмерно развивающийся про- 
цесс экономической, социальной и политической интеграции, характеризующийся основательным разрастанием ТНК.

Отечественные ученые отмечают, что ТНК превратили мировую экономику в транснациональное производство, эскалируя процесс экономической глобализации [7].

ТНК стали основными игроками мировой экономики за счет роста количества собственных филиалов во всем мире, патентов на новые технологии и изобретения, использования механизма стратегического альянса - тесного взаимодействия и разграничения объектов ведения между собой.

Для контроля инновационной деятельности международных корпораций на территории России государству следует вести контроль по соблюдению предприятиями с иностранным капиталом регламентированных требований об использовании в процессе собственного производства конкретных товаров отечественной промышленности в определенных объемах и национальной рабочей силы, закупка импортных товаров также должна находиться в определенной пропорции с объемом экспорта отечественной продукции.

Правительство РФ должно способствовать созданию в государствах инвестиционных союзов - частных неполитических организаций, способных привлечь иностранные инвестиции в капиталоемкие области экономики определенной страны на долгосрочной основе [3].
Таким образом, международные корпорации представляют собой достаточно сложное и постоянно развивающееся явление в системе мирохозяйственных связей, требующее особого внимания со стороны как отдельно взятых государств, так и международного контроля, особенно в современных экономических условиях, благоприятствующих развитию транснациональных компаний.

Подводя итог, целесообразно сформулировать следующие выводы:

- в условиях глобализации экономики влияние международных корпораций на развитие инновационных технологий в России является значительным;

- инновационная деятельность международных корпораций в России развивается в трех ключевых направлениях: регистрация патентов с целью трансфера технологий в другие страны, сотрудничество с научно-исследовательскими институтами, совместные проекты с отечественными предпринимательскими структурами инновационного характера;

- инновационная деятельность международных корпораций в России имеет как экономические, так и социальные эффекты. Для оценки степени воздействия международных корпораций на формирование инновационной экономики в стране целесообразно применять комплекс показателей.

\section{ЛИТЕРАТУРА}

1. Бак Г.А. Инновационные стратегии транснациональных корпораций в отдельных секторах мирового хозяйства // Креативная экономика. 2013. № 8 (80). С. 31-38.

2. Венцетель М. В. Стратегии развития транснациональных корпораций в мировой экономике // Вестник Российского экономического университета им. Г.В. Плеханова. Вступление. Путь в науку. 2017. № 1 (17). С. 6-14.

3. Давыдов Д.О. Развитие интеллектуального капитала транснациональных корпораций в условиях новой волны глобализации // А-фактор: научные исследования и разработки (гуманитарные науки). 2020. № 1. С. 3

4. Инвестиции в России-2017 // Росстат [Электронный ресурс] - Режим доступа: http://www.gks.ru/bgd/regl/b17_56/Main.htm (дата 0бращения 24.03.2018).

5. Кабанова 0.Н. Инновационная деятельность ТНК как фактор развития российской экономики // Экономика. Бизнес. Банки. 2012. Т. 4. С. 77-85.

6. Капустина Л.М., Фальченко О.Д. Транснациональные корпорации: роль в экономическом развитии России. - Екатеринбург, 2015. - 164 с.

7. Любимов И.С. Проблема транснационализации в современной мировой экономике // Державинский форум. 2017. № 2. С. 32-37.

8. Сарибекян Т.А. Инвестиционная деятельность иностранных ТНК в России // Проблемы социально-экономического развития России на современном этапе / Материалы IX ежегодной Всероссийской научно-практической конференции (заочной) с международным участием: в 2 частях. 2016. С. 205-210.

9. Шавина Е.В. Инновационная деятельность глобальных корпораций в России и российских ТНК за рубежом // Вестник Российского экономического университета им. Г.В. Плеханова. 2012. № 8. С. 19-27.

() Федченко Анастасия Марковна ( nestezzy@mail.ru ).

Журнал «Современная наука: актуальные проблемы теории и практики» 